Trials and tribulations of PhD students

Sir - Your reports of the suicide of Jason Altom, a student at Harvard University, crystallized some thoughts about the frustrations of many graduate students (Nature 395, 823, 826; 1998 \& 397, 291; 1999).

Tragedies like this are known at almost all research universities. It is surprising how much control supervisors can exert over their students' careers, and bad relations with supervisors are nightmarish. There are many factors that individually may seem innocent, but which can have disastrous cumulative effects. One of these is the system of recommendations (references).

Throughout a postgraduate scientific career, recommendations are required, and that of one's $\mathrm{PhD}$ supervisor is almost indispensable. Applicants will obviously try to submit only positive recommendations, so this system is inherently biased and subjective. As long as one has a friendly and objective supervisor, all is well. But a student who has strained relations with their boss is at an unfair disadvantage.

I know of many students who cannot speak out against their mentors even after finishing their $\mathrm{PhD}$, largely because they will need references in the future. This breakdown might be read as an inability to maintain professional relations, but such relations are a two-way street.

References should be less important, and hiring choices should be decided by more objective parameters such as test scores, quality of work and publications, and personal interviews. Sympathetic professors and graduate programmes should try to put this into practice as soon as possible, and encourage others to do so. Sudhanshu Dole

Institute for Genetics, University of Cologne, 121 Weyertal, Cologne 50931, Germany

Sir - When I was an MSc student in Canada, I was the president of 100 graduate students, and frequently heard about or counselled those who had suffered verbal abuse, threatening remarks, and many other abuses at the hands of their supervisors. The problem is a Pandora's box.

After hearing so many complaints, I devised a form on which graduate students could evaluate their supervisors. But it was overwhelmingly turned down by the committee of my fellow students, who were afraid that negative remarks would harm their relationships with their supervisors and subsequent letters of reference. At that point, I became known among my fellow students as the guy who wanted to expose departmental practices.

I then moved to a prominent university in England to study for a $\mathrm{PhD}$. I soon learned that things can be even worse. There is rarely any undergraduate evaluation here, and the role of graduate supervisors (of which there is almost always only one) is usually minimal. The supervisor gives you a project and expects results - plain and simple. Fortunately, my supervisor cares about my development as a scientist, but he is a rare example.

I believe that further cases like that of Altom can be avoided if prospective students know the track record of the proposed supervisor and the potential for abuse. I urge the formation of an international, independent directory of graduate evaluations of supervisors. Name and address supplied

\section{How hunger keeps the population down}

Sir - Stephen G. Warren and Roger Short leave the reader puzzled about how the volume of agricultural output sets limits to the size and growth of human population (Nature 397, 101; 1999). Both authors agree with Malthus that such limit-setting occurs, but Short shows that it does not operate through hunger reducing women's fertility. But surely famine and malnutrition sharply increase child mortality, thereby reducing recruitment to the ranks of sexually mature women and so rendering population growth impossible.

The increase in food production began in Europe in the seventeenth and eighteenth centuries and, at least initially, owed more to better organization than to science.

Hermann Bondi

Churchill College, Cambridge CB3 ODS, UK

\section{Revolutionary ideas} \section{come round again}

Sir - Plus çà change. Editorials in Nature ${ }^{\mathrm{T}-3}$ pointing out that the studies of many molecular biologists have been largely qualitative are one thing, and very welcome.
However, it is quite wrong to comment ${ }^{3}$ that "the biologist ... will probably have had very little quantitative training", since at least those biochemists who deal with enzymes and metabolism must of necessity work properly with numbers.

The post-genomic era will certainly be characterized by large-scale and quantitative analyses, but it is the large scale that is new, not the quantitative aspect. Sensitivity analysis, which is what Alon et al. ${ }^{4}$ have done, has been a tool of biochemistry for a quarter of a century ${ }^{5-7}$. Robustness and rigidity against large changes in fluxes following changes in enzyme levels are a well-established property of metabolic networks ${ }^{8}$ that follows naturally from their structure and kinetic properties ${ }^{9}$.

But etymologically you are correct; if quantitative methods in biology are a "revolution" it is only because they are coming round again.

Douglas B. Kell

Institute of Biological Sciences, Cledwyn Building, University of Wales, Aberystwyth SY23 3DD, UK

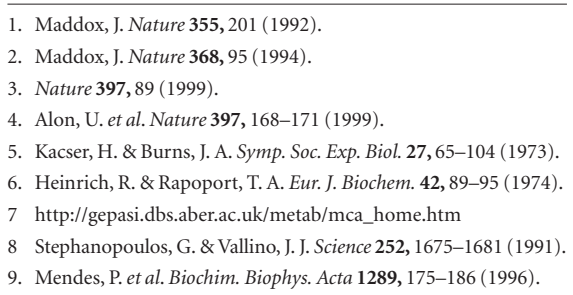

\section{Patent attorneys pay their way}

Sir - A journal of Nature's calibre should be above taking cheap shots at attorneys in general and patent attorneys in particular. In your editorial on the sharing of research materials, advocating the use of uniform materials transfer agreements, the final sentence was unnecessary, unprofessional, and sorely weakened an otherwise cogent, if misguided, argument (Nature 396, 97; 1998).

"No one need lose but the lawyers"? A little simplistic, don't you think? Especially in the light of the fact that it is patent attorneys who provide the written record, in the form of granted patents, that allows both private and public organizations to generate revenues from their discoveries. In an era of shrinking public funding of basic scientific research, these revenues are an indispensable tool to fund research.

Failing to protect such resources will cause unwary research organizations to incur significant losses. By denigrating the role of patent lawyers in protecting valuable intellectual property, you have done your readers a grave disservice.

Joseph T. Leone

DeWitt Ross \& Stevens, 8000 Excelsior Drive, Suite 401, Madison, Wisconsin 53717-1914, USA 